\title{
Uncovering the pathways to e-learning success: A qualitative approach
}

\author{
Nuno Pena, ISEG - University of Lisbon, Portugal, npena@iseg.ulisboa.pt \\ Carla Curado, ISEG - University of Lisbon, Portugal, ccurado@iseg.ulisboa.pt
}

\begin{abstract}
This paper reports a qualitative study on the effectiveness of an e-learning framework (IPTEACES) for Insurance Broker Training Program Certifications, using a sample of 3,726 trainees from 16 different corporations from insurance and banking industries in Portugal. We've applied fuzzy-set Qualitative Comparative Analysis ( $\left.f_{s} Q C A\right)$ technique, which offers improved results when compared to the use of quantitative traditional statistical methods (e.g. regressions, structural equations modeling) that only provide an estimated solution to the dependent variable at stake. Findings suggest higher training success levels are achieved by: older, more educated women trainees attending banking training events covering a large breadth (double course). Concerning lower training success results, evidence shows that those are achieved by: less educated male trainees, attending insurance training events covering a single course. These study results are consistent with previous reported work that followed a quantitative approach.
\end{abstract}

Keywords: Instructional design framework, e-learning, training success, fuzzy-set Qualitative Comparative Analysis (fsQCA).

\section{Overview of IPTEACES framework}

Involvement, Preparation, Transmission, Exemplification, Application, Connection, Evaluation, and Simulation (IPTEACES) is an e-Learning Framework conceived to facilitate e-learning by reducing diversity in programs facing a non-homogeneous audience (Pena \& Isaias, 2012; Pena \& Isaias, 2013). This instructional design framework was primarily developed through a pedagogical benchmark, mainly Gágne's Nine Events of Instruction (Gagné, Briggs, \& Wager, 1992), Merrill's Principles of Learning (Merrill, 2002; 2007), Keller's ARCS's model Keller (2008), as well as van Merrienboer and Kirschner's (2007) Ten Steps to Complex Learning, and by investigating award winning e-courses (e.g. Brandon Hall Excellence in Learning Awards, International e-Learning Association Awards) and corporate e-learning best practices (e.g. Bersin \& Associates).

A - Front-End Procedures - For a student to attend an e-learning course it is necessary that s/he possesses the necessary technical requirements. To transform these technological requirements (ex. browser, software versions, screen resolution, pop-up windows, etc.) into transparent and intuitive information to the learner, this phase is divided in two parts: "Browser Check" and "Help Desk". These complementary sub-phases intend to demystify any technological complexity for the end user. In this sense, it was developed a "Browser Check" functionality that runs a script that automatically diagnoses the student's browser and installed software and indicates the need or not for an additional configuration or software installation. This procedure guaranties that the student 
has the minimal requirements to access the e-learning course. Furthermore, the student is invited to directly contact the HelpDesk by phone or by email in case of help needed in these procedures.

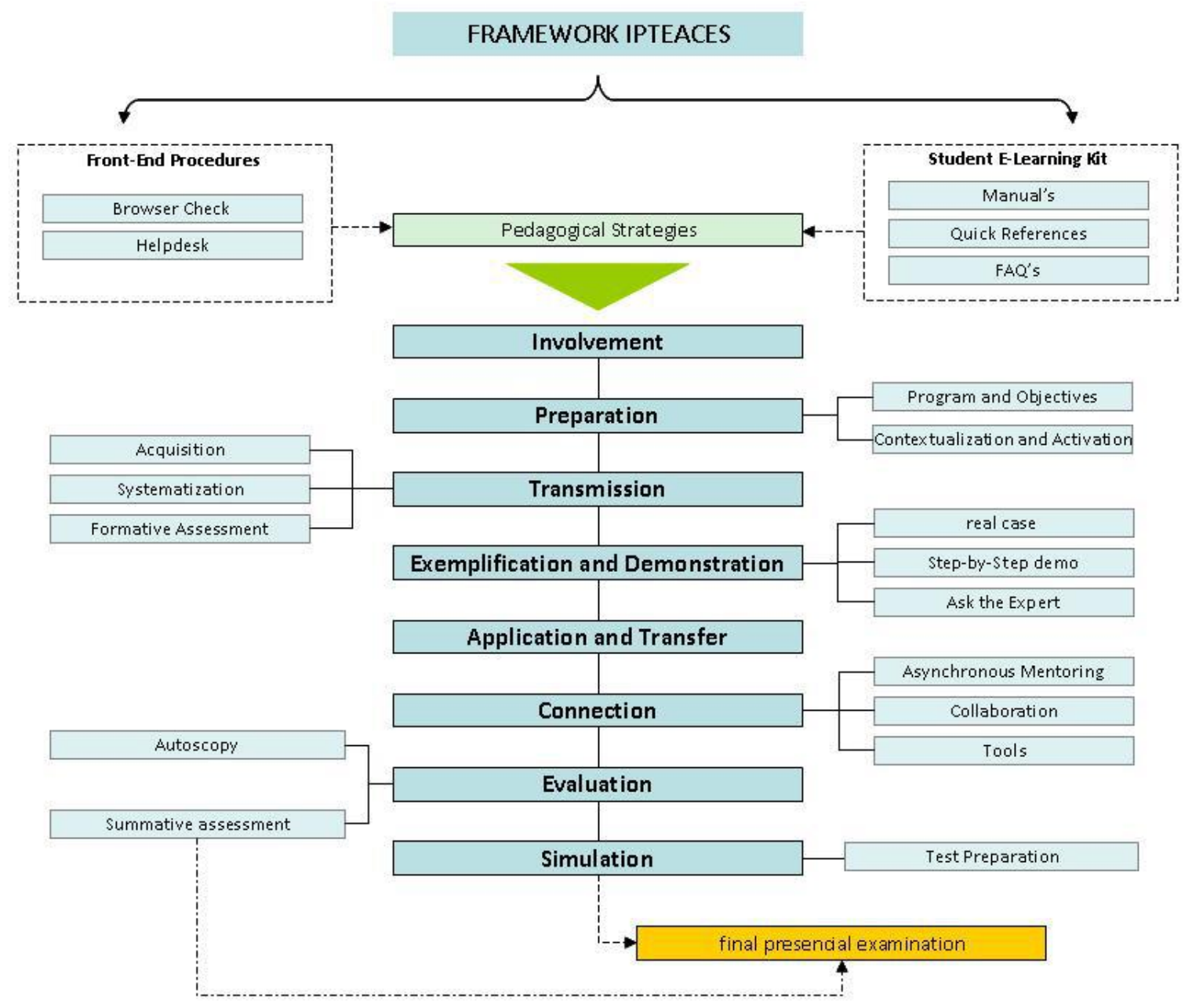

Figure 1. The IPTEACES Framework

B - Student e-Learning Kit - Manuals, Quick Reference Guides and FAQ's: It is important for the student to have access to information concerning how to access and navigate in the Learning Management System (LMS) as well as in the Course, therefore, manuals are provided. However, students don't always explore these materials before accessing the course. To minimize this constraint, it was developed an instrument where, in the form of an animated step by step demonstration, the student observes how to access the course, to navigate in the course as well as an overview of the course's main functionalities (Quick Reference Guide). In other words, it is given to the students, in a quick and clear format, the minimal and essential steps. Similarly, it was transformed the traditional Frequently Asked Questions (html or pdf) in animated (flash movie) responses to the students. The reading paradigm/approach was complemented with an easier and quicker form: the "animation/observation" mode. 


\section{Pedagogical Strategies (Detail of the IPTEACES Framework):}

- Involvement - This strategy aims to immerse the student in the context of business scenario, where s/he is confronted with a specific corporate problem (Merrill, 2002; 2007) or with a job situation to be resolved. The student will play a role in a relevant business situation. The character dialogues and interacts, along the course, with others that will appear several times throughout the course and sets up a short narrative in the form of dialogue. From a pedagogical point of view, it seeks to 'gain the attention of the student' ( $c f$. - Gagné's first event "Gaining Attention"; Keller's first principle of ARCS -"Motivation to learn is promoted when a learner's curiosity is aroused due to a perceived gap in current knowledge"), surrounding and projecting him in a situation that simulates real, enhancing motivation and making a connection with everyday workplace problems.

- Preparation - This strategy is divided into two complementary phases: Presentation of "Program and its Objectives" and "Contextualization and Activation":

a) Program and its Objectives - Presentation of the program, objectives and what is expected of the student ( $c f$. - Gagné's second event "Informing the learner of the Objective"; Keller's second principle: "Motivation to learn is promoted when the knowledge to be learned is perceived to be meaningfully related to one's goals"). It is necessary to inform and make sure that the learner understands, in detail, the relevance of the course, as well as what is expected of him. This approach details the generic objectives and goals into small chunks that are objective and measurable, i.e., into specific objectives.

b) Contextualization and Activation - Before starting the "Transmission" phase (learning content), this strategy seeks to make an introduction, a contextualization or a reminder of the subject (or related / prerequisites) so the student can activate prior existing knowledge (cf. - Gagné's third event Stimulating Recall of Prerequisite Learned Capabilities; Merrill's Activation principle - Learning is promoted when learners activate relevant cognitive structures by being directed to recall, describe, or demonstrate relevant prior knowledge or experience. Activation is enhanced when learners recall or acquire a structure for organizing the new knowledge. In other words, seeks to establish relationships between new concepts or new information and concepts and existing knowledge or with some prior experience.

- Transmission - This phase is divided in three complementary phases: Acquisition (learning content), Systematization, and Formative Assessment.

Acquisition is the central strategy for presenting the new learning content. This strategy (Gagné's fourth event Present the Stimulus Material) is where the new content is actually presented to the learner. Content should be chunked and organized meaningfully to appeal to different learning modalities, using a variety of media - including text, graphics, audio narration, and video, regarding the main recommendations from Cognitive Load Theory (Clark, Nguyen, \& Sweller, 2006). After presenting a part of new learning contents, related to one specific objective ( $c f$. Program and objectives phase), it is advisable to carry out a systematization through a summary of concepts and ideas taught. It is also advisable to create a graphical representation of the 
relationship between the concepts and ideas (new learning material) through the use of "concept maps" (showing the relationships among concepts ) or "dynamic diagrams."

- Exemplification and Demonstration - This phase is mainly based on Merrill's (2002; 2007) "demonstration principle" and it was divided into three complementary sub-strategies: Real Case, Step-by-Step demo, and Ask the Expert.

a) Real Case is an exemplification based on real cases, real situations, real problems, and looks for confronting learners with authentic real-life situations, while it tries to illustrate the relevance of the content and searches to demonstrate the concepts learned.

b) Step by step demo is a type of guided exemplification ( $c f$. Gagné's fifth event Providing learning guidance) that seeks to illustrate the decomposition of a problem into constituent parts and components, while demands a detailed and commented analysis of the parts that compose the complexity of a situation, of a problem.

c) Ask the expert is a type of more complex situation, a structured example in which, faced with a problem, the student may ask advice from the expert on how the problem could / should be resolved.

Demonstrations are enhanced when learners receive guidance that relates instances to generalities, and when learners observe media relevant to the content. Merrill (2007) summarized this "third principle" as "Show me". Show me involves both demonstration and guidance. Effective guidance involves steering learners to relevant information and helping them to compare a variety of demonstrations.

- Application and Transfer - This phase focus on the effort to maximize the transfer of learning, for the promotion of the ability to flexibly apply what has been learned in new situations (cf. Gagnés fifth and sixth event - Eliciting learning guidance and Providing feedback; Keller's third principle Confidence and Merrill's Application principle). As referred by Merriënboer and Kirschner (2007), the fundamental problem facing instructional designers is education and training's apparent inability to achieve the transfer of learning. This phase is an opportunity for the learner to apply the learned knowledge or skill, first with guidance and gradually without guidance and receiving sustainable feedback and support. This phase is mainly based in Merrill's Application principle - Learning is promoted when learners engage in the application of their newly acquired knowledge or skill that is consistent with the type of content being taught. Application is effective only when learners receive intrinsic or corrective feedback, and when learners are coached and when this coaching is gradually withdrawn for each subsequent task. This is also complementary to what Keller considered in his third principle, "Motivation to learn is promoted when learners believe they can succeed in mastering the learning task". Confidence, the third ARCS category, incorporates variables related to student's feelings of personal control and expectancy for success. 
- Connection - This phase focuses on mentoring, collaboration and tools.

a) Asynchronous Mentoring: Along the course, students may face some specific questions that are needed to be clarified. In this sense it was developed an integrated e-mail functionality inside the course in order for the student to question their tutor -asynchronous mentoring through direct email.

b) Collaboration: there are two kinds of discussion forums available: Supervised discussion Forums' and Peer discussion forums'. In each learning module, there is always available a Supervised Discussion Forum. In this Forum, all the posts are visible to everyone in the e-learning class, which is divided by small groups, and connected with their associated tutor. Peer discussion forums are also available without direct supervision of the tutor. Here students can exchange ideas, doubts, materials and get connected and feel as part as an e-learning class.

c) Tools: This feature complements the contents of the course and gives the student access to a glossary of terms, job aids, documentation, worksheets, templates, articles, legislation and other pragmatic materials.

\section{- Evaluation: Autoscopy and Summative evaluation}

At the end of each learning module, the system suggests that the student submit a Self-Assessment. The intention is to determine whether the student, in his/her opinion, has achieved the learning objectives. Upon completing the modules, students are required to undertake a final assessment. This test, a summative evaluation, is intended to assess objectively whether the student has achieved the specific objectives of each of the learning modules. A detailed feedback follows the results of the summative assessment. Students can see their classification (score); note the questions that are correct or incorrect; compare their answer with the accurate response. This process creates a direct learning path that addresses any gaps in the learning.

This strategy relates directly to Gagné's eighth event, Assess Performance, and to Keller's fourth principle "Motivation to learn is promoted when learners anticipate and experience satisfying outcomes to a learning task" - which is represented in the ARCS model by Satisfaction. It is necessary for learners to have positive feelings about their learning experiences and to develop continuing motivation to learn.

\section{- Simulation}

A common definition of a simulation is a reproduction of an item or event. A true simulation has a specific goal in mind - to mimic, or simulate, a real system so that we can explore it, perform experiments on it, and understand it before implementing it in the real world. It provides an immersive learning experience. A simulation exam was devised similar to the one that the candidates need to pass in the face-to-face examination after successfully completing all the elearning modules. This strategy takes into account Gagne's nine event (Enhance retention and transfer to the Job) and especially Merrill's Integration Principle, - Learning is promoted when learners integrate their new knowledge into their everyday life by being directed to reflect on, discuss, or defend their new knowledge or skill. Also, Keller contends that motivation to learn is 
promoted and maintained when learners employ volitional (self-regulatory) strategies to protect their intentions - after becoming motivated to achieve a goal, it is necessary to persist in one's efforts to achieve it, which is the focus of this principle.

\section{Training Program Characteristics}

Studies often demonstrate the influence of the demographic characteristics and the relationships between these characteristics on the students' achievement. Students can be influenced by socialdemographic characteristics such as age, gender, education level, in order to be effective (Cercone, 2008; Cavus \& Ibrahim, 2007; DeBaz, 1994; Grissom, 2004; Kara, Bagheri, \& Tolin, 2011; Musa \& Othman, 2012; Park \& Choi, 2009; Wilson \& Allen, 2011; Xu \& Jaggars, 2013).

For example, Jaeger and Eagan (2007) as well as Cole and Espinoza (2008) found gender differences in the academic performance of male and female students. Keith, Byerly, Floerchinger, Pence, and Thornberg (2006) found positive relationship between age and academic performance. However, Kaur, Chung, and Lee (2010) found that age does not significantly contribute to academic performance of university students in distance learning (e-learning). This is particularly decisive when training projects use Online Distance Learning (e-learning). To analyze the rate of accomplishment of our goal, we felt necessary to further deepen the understanding as to which group or groups was/were IPTEACES e-learning framework most effective. In this sense, based on the most relevant success criteria (final exam scores) we intended to determine the impact that this framework had among the socio-demographic characteristics previously identified (industry, gender, age groups, education level), to identify the trainee profiles associated to higher final scores, as well as the less successful ones.

\section{Methods}

We developed a qualitative approach to data using fuzzy set Qualitative Comparative Analysis (fsQCA) aiming to identify the necessary, the sufficient and the core conditions among data. fsQCA uncovers the configurations leading to the outcome variable - in this study Training success (Trai) - as well as the absence of it ( Trai) (represented by the use of $\sim$ previous to the outcome). We've applied fsQCA technique, which is an improvement compared to the use of quantitative traditional statistical methods (e.g. regressions, structural equations modeling) that only provide an estimated solution to the dependent variable (Rihoux \& Ragin, 2009).

On the contrary, fsQCA accepts that conditions can be causally related in one configuration yet, they can be unrelated or even inversely related in others (Meyer, Tsui, \& Hinings, 1993). fsQCA accepts alternative combinations of causal conditions, equifinality and asymmetry (Fiss, 2011) which, applied to the present case, allows for more than one combination (or configuration) of causal conditions leading to Trai; alternative causal configurations can contribute to Trai, and causal conditions of training success may differ from causal conditions of its absence.

Causal conditions in the fsQCA analysis are related to each training event and as well as to the trainees. The conditions related to each training event are Course amplitude (Amp) and Course topic (Top), whereas the conditions related to the trainee are Age (Age), Gender (Gen) and Education level $(E d u)$. Since training success is the result of complex relations and students' achievements can be influenced by social-demographic characteristics (Cercone, 2008; Cavus \& Ibrahim, 2007; DeBaz, 1994; Grissom, 2004; Kara, Bagheri, \& Tolin, 2011; Musa \& Othman, 
2012; Park \& Choi, 2009; Wilson \& Allen, 2011; Xu \& Jaggars, 2013), the use of fsQCA is adequate for it presents the ability to address complex structures (Basedau \& Richter, 2014). Each configuration of causal conditions and the associated outcome are designated as a case (Fiss, 2007).

\section{Data collection}

This study uses data from an e-learning project (Insurance Broker Training Program Certifications - General, Life, Non-life \& Reinsurance) that used IPTEACES e-learning framework, on a sample of 3,726 employees from sixteen different corporations from the insurance and banking industries in Portugal. Below, we describe an overview of the socio-demographic characteristics of the attendees:

- Industry: 1,614 learners (43.3\%) came from the insurance industry and 2,112 learners $(56.7 \%)$ from the banking industry;

- Gender: 1,953 male learners (52.4\%) and 1,773 female learners (47.6\%);

- Age groups: Average of 34 years old, with a standard deviation of 8.8 years. Learners range from 18 years old to 71 years old. The major (51\%) age category is the one between '24 and 34' years old;

- Education Level: Graduate and Post graduate degrees 1,548 (41.5\%); Primary, Secondary and Undergraduate degrees 2,178 (58.5\%).

Among the 3,726 learners who attended the Insurance Broker Training Program Certifications General, Life, Non-life and Reinsurance, 3,542 passed the final on-site exam (approbation rate of 95.0\%), and 184 failed and dropped-out (failure rate of 5\%). More precisely, concerning the three exam possible sessions, 3,100 learners (83.2\%) were approved on the first exam attempt, 382 learners were approved on the second exam session (10.2\%), and finally 60 learners on the third exam session (1.6\%); 184 learners dropped-out. The global average score of the learners was $82.5 \%$, with a standard deviation of 11.0 .

\section{Calibration}

Qualitative comparative analysis was developed originally for the analysis of configurations of crisp sets i.e., conventional Boolean sets. When using crisp sets the researcher has got a simple data sets composed of binary conditions, coded 1 for "present" and 0 for "absent". Some of the conditions considered in the study are binary, and thus they compose the crisp set in the study. For such conditions there is no necessity for long calibration process. Calibration of crispy-sets is straight forward; a case is simply either in or out of any set (Ragin, 2006). Binary variables are accepted for fsQCA use, as crispy-set variables (full membership = 1 \& full non-membership = $0)$.

Regarding conditions that are not crisp in their essence and assume other values apart for 1 and 0 , calibration is needed; such conditions compose the fuzzy set. Calibration is the process of classifying conditions in each case from full membership (1.00) to full non-membership (0.00). The outcome variable - training success - was also calibrated. fsQCA use requires data to be 
calibrated, so that the different variable levels represent meaningful groups (Crilly, Hansen, Pedersen, \& Perrini, 2012; Ragin, 2008;). Calibration implies a theoretical and empirical knowledge on the variables (Ragin, 2008). Categorical variables are accepted for fsQCA use, each category must be associated to a meaningful group (full membership, crossover point of maximum membership ambiguity, \& full non-membership, this calibration implies a theoretical and empirical knowledge on the variables (Ragin, 2005; 2008).

Fuzzy membership scores address the varying degree to which different cases belong to a set. Thus, fuzzy sets assess varying degrees of membership between full inclusion and full exclusion. In this sense, a fuzzy set can be seen as a continuous variable that has been purposefully calibrated to indicate degree of membership in a well-defined set. Such calibration is possible only through the use of theoretical and substantive knowledge, which is essential to the specification of the three qualitative breakpoints: full membership, full nonmembership, and the point of maximum ambiguity regarding membership (Ragin, 2005).

Following Ragin (2008), we have defined the three different anchors that are necessary to calibrate survey data to fuzzy-set values establishing the degree of membership of each score; 0.95 for the threshold for full membership; 0.5 for the crossover point of membership ambiguity, and 0.05 for the threshold for full nonmembership. In order to calibrate fuzzy set data we calibrated the causal condition (age) and the outcome (training success) the manual way, based on theoretical assumptions and the interpretation of data, and thus, attending to particularities of the variable's descriptive statistics. Table 1 (missing data reduced observations to 3,676) shows the conditions in the study and the cuts used for calibration for the fuzzy set; for each condition it presents the descriptive statistics and the scores regarding the three different thresholds for calibration when applied.

Table 1. Descriptive statistics $(n=3,676)$ and calibrations of causal conditions and outcome

\begin{tabular}{|c|c|c|}
\hline Causal conditions and outcome & Descriptive Statistics & $\begin{array}{c}\text { Calibrations } \\
(0.95 ; 0.50 ; 0.05)\end{array}$ \\
\hline Course amplitude (Amp) & $\begin{array}{c}\text { Binary variable; } \\
\text { 1= Double Course Life and Non- } \\
\text { life; } 0=\text { Single Course Life or } \\
\text { Non-life }\end{array}$ & --- \\
\hline Course topic (Top) & $\begin{array}{c}\text { Binary variable; } \\
1=\text { Insurance; } 0=\text { Banking }\end{array}$ & --- \\
\hline Gender (Gen) & $\begin{array}{c}\text { Binary variable; } \\
1=\text { Female; } 0=\text { Male }\end{array}$ & --- \\
\hline Education level (Edu) & $\begin{array}{c}\text { Binary variable; } \\
1=\text { Graduate; } 0=\text { Undergraduate }\end{array}$ & --- \\
\hline Age (Age) & $\begin{array}{c}\mu=34.35 ; \sigma=8.939689 ; \min = \\
18 ; \max =71\end{array}$ & $(51 ; 35 ; 23)$ \\
\hline Training success (Trai) & $\begin{array}{c}\mu=81.49 ; \sigma=12.55159 ; \min = \\
34 ; \max =100\end{array}$ & $(98 ; 82 ; 64)$ \\
\hline
\end{tabular}

$\mu=$ average, $\sigma=$ standard deviation, $\min =$ minimum, $\max =$ maximum 


\section{Necessity and Sufficiency Analysis}

Causal conditions are assessed for necessity and sufficiency. The causal condition's degree of necessity indicates the extent to which it is needed to achieve the outcome. Conversely, the causal condition's degree of sufficiency shows the extent to which it can be related to the explanation of the outcome (Fiss, Sharapov, \& Conqvist, 2013). The sufficient condition sets are also designated as configurations (of several causal conditions leading to the outcome variable).

Necessary conditions should present a consistency score exceeding the threshold of 0.80 (Ragin, 2000). When addressing the necessary conditions, regarding the presence of the outcome (Trai) the only existing necessary condition is Course amplitude (Amp). Regarding the absence of the outcome ( Trai) there are no necessary conditions.

When addressing the sufficient condition sets, and regarding the presence of the outcome (Trai), results show three parsimonious causal combination and three intermediate ones (for debate among complex, parsimonious, \& intermediate solutions see Fiss (2011) \& Ragin (2008)). All the configurations as well as the parsimonious and the intermediate solutions regarding the presence of the outcome (Trai) present consistency levels above 0.864806 (Table 2) complying with the threshold of 0.80 suggested by Ragin (2008), Crilly (2011), or Fiss (2011).

Considering the sufficient condition sets, and regarding the absence of the outcome ( Trai), results show two parsimonious causal combinations and two intermediate ones. All the configurations as well as the parsimonious and the intermediate solutions regarding the absence of the outcome ( Trai) present consistency levels above 0.820215 (Table 3 ) respecting the threshold of 0.80 suggested by Ragin (2008), Crilly (2011) or Fiss (2011). Consistency reflects the extent to which the cases share a given combination of conditions agree in presenting the outcome in question (Ragin, 2008). Coverage reflects how much of the variation in the outcome is accounted for by a causal condition or combination (Ragin, 2006) similar to the $\mathrm{R}^{2}$ regarding linear regressions (Fiss et al., 2013). Specifically, unique coverage shows the relative importance of each particular configuration (Fiss, 2011).

\section{Causal Configurations}

Following the best practices, we report the configurations (Table 2) presenting the causal combinations for the outcome variable (Trai), as well as (Table 3) the causal combinations for the absence of the outcome variable ( Trai). Core conditions are the ones included in both the parsimonious and intermediate solutions, while peripheral conditions are only part of the intermediate solution (Fiss, 2011; Fiss et al., 2013; Ragin 2000, 2008). The most parsimonious solution contains only core conditions highly linked to the outcome. The intermediate solutions are more conservative assuming the most plausible simplifying assumptions (Ragin, 2008). 
Table 2. Causal configurations for Training success (Trai)

\begin{tabular}{|c|c|c|c|c|c|c|c|c|}
\hline \multicolumn{4}{|c|}{ Coverage } & \multicolumn{4}{|c|}{ Consistency } & \\
\hline Configurations & Amp & Top & Edu & Age & Gen & Raw & Unique & \\
\hline 1 & $\bullet$ & 0 & 0 & 0 & & 0.102838 & 0.041965 & 0.899952 \\
\hline 2 & 0 & 0 & & $\bullet$ & 0 & 0.140690 & 0.079817 & 0.867493 \\
\hline 3 & - & & ? & 0 & - & 0.088973 & 0.028100 & 0.897412 \\
\hline
\end{tabular}

Overall Solution coverage: 0.210754

Overall Solution consistency: 0.864806

Amp $=$ Training amplitude; Top $=$ Training topic: Edu $=$ Education level; Age $=$ Age; Gen $=$ Gender; full black circles $(\bullet)$ indicate the presence of a condition, and center white circles $(O)$ indicate its absence. Configurations in Table 2 include only core conditions. Blank spaces indicate "don’t care."

Table 3. Causal configurations for the absence of Training success ( Trai)

\begin{tabular}{ccccccccc}
\hline \multicolumn{8}{c}{ Coverage } & \multicolumn{2}{c}{ Consistency } & & \\
\hline Configurations & Amp & Top & Edu & Age & Gen & Raw & Unique & \\
\hline 1 & $\bigcirc$ & $\bullet$ & $\bigcirc$ & & & 0.131349 & 0.025138 & 0.830247 \\
\hline 2 & $\bigcirc$ & $\bullet$ & & & 0 & 0.180357 & 0.074146 & 0.829912 \\
\hline
\end{tabular}

Overall Solution coverage: 0.205496

Overall Solution consistency: 0.820215

Amp $=$ Training amplitude; Top $=$ Training topic: Edu $=$ Education level; Age $=$ Age; Gen $=$ Gender; full black circles $(\bullet)$ indicate the presence of a condition, and center white circles $(O)$ indicate its absence. Configurations in Table 3 include only core conditions. Blank spaces indicate "don’t care."

\section{Discussion}

There is a single necessary condition regarding Trai: which is Amp. The course amplitude seems to be an important antecedent to training success. Courses with a larger breadth tend to lead to better training success. Such results are consistent with a previous study that used a quantitative method approach over the same data set (Regression Tree using exhaustive CHAID algorithm).

Results reflect the described assumptions of fsQCA:

a) more than one configuration of causal conditions lead to either the outcome and its absence (alternative combinations of causal conditions).

There are three pathways leading to training success. Pathway 1: Amp; Top; Edu; Age. According to such configuration, banking training events that cover a large breadth and have older and more graduated/educated trainees seem to reach higher levels of training success. Pathway 2: Amp; Top; Age; Gen. According to such configuration, banking training events that cover a large breadth and have older women trainees appear to generate higher levels of training success. Pathway 3: Amp; Edu; Age; Gen. According to such configuration, training events that cover a large breadth and have older and more graduated/educated women trainees seem to conduct to higher levels of training success. Concerning similarities among these three pathways, it seems there is a dominant influence (the presence of the Age condition on all three pathways); older trainees tend to achieve better training success.

Furthermore, based on resemblances between the three pathways, it seems, women (the presence of the Gen condition on two pathways) and older trainees tend to achieve training success when 
attending banking training events covering a larger breadth (the presence of the Age and Amp conditions on all pathways). Additionally, it seems that more educated trainees tend to achieve training success (the presence of the $E d u$ condition on two out of three pathways). Such results are consistent with \{Removed for Refereeing\}. Such results are encouraging because they show training managers that there are several configurations (3) leading to training success.

There are two pathways leading to less successful training results. Pathway 1: Amp; Top; $\sim E d u$. According to such configuration, insurance training events that cover a short breadth and have less graduated/educated trainees seem to reach less successful training results. Pathway 2: Amp; Top; $\sim$ Gen. According to such configuration, insurance training events that cover a short breadth (there is the $\sim A m p$ condition on both pathways) tend to lead to less successful training results. Men trainees seem to reach less successful training results (there is the $\sim$ Gen condition on a pathway), as well as, having less educated trainees (there is the $\sim E d u$ condition on a pathway). Regarding similitudes among these two pathways, some common evidence arises; trainees' age is not a causal condition to less successful training results. Moreover, it seems shorter breadth training events tend to lead to less successful training results. There are alternative combinations of causal conditions leading to training success (three), and to less successful training results (2) confirming this fsQCA assumption. Regarding the difference between the two findings, pathways to training success emphasize, while pathways leading to less successful training results.

Such findings are consistent with previous results Framework (Pena \& Isaias, 2012), according to which "Industry" emerged as the primary criteria for final scores differentiation. Trainees from the insurance industry have, on average, significantly different final grades from banking industry trainees. Concerning the Banking Industry, results showed, firstly, that the age is the first breaking down variable, resulting in three sub-groups. Older students scored higher (on average 86.6\%). The above level of the regression tree, showed also that education level influences trainees success. Trainees with the top education level reached the highest average scores of $83.8 \%$. Regarding the Insurance Industry, results distinguished the trainees with highest education level scored higher (on average $82,9 \%$ ).

Finally, it seems insurance training events appear to reach less successful training results. Such results are consistent with previous empirical work. Comparing configurations leading to the outcome and its absence, it seems the former (training success) includes both training program characteristics and trainees' characteristics, whereas the latter (less successful training results) includes mainly training program characteristics. Such results bring clear lessons for human resources $(\mathrm{HR})$ and training managers: training success depends on both the program and the trainees, while less successful training results originate essentially from program characteristics.

b) alternative causal configurations can produce the same outcome (equifinality). There is evidence in support of equifinality, since there are several pathways leading to the outcome and its absence. The use of this technique provides causal combinations leading to the outcome (training success), which is an advantage compared to traditional statistical methods that provide single estimated solutions. While there are three pathways to training success, each one involves four causal conditions. Such evidence represents a challenge for HR and training managers when preparing training events, they have to satisfy four conditions, as a consequence pathways to training success seem to be demanding. Although there are just two pathways to less successful 
training results, each one involves only three causal conditions. Such evidence should represent an alert for HR and training managers when preparing training events, since pathways to less successful training results involve fewer conditions, and thus easier to occur.

c) causal conditions of the outcome may differ from causal conditions for its absence (asymmetry). Antecedents of training success may differ from antecedents of less successful training results. The use of this technique provides causal combinations leading to the absence of the outcome (less successful training results), which is an advantage compared to traditional statistical methods that deliver a single estimated solution regarding the desirable outcome. Results provide pathways to training success and well as the trails to less successful training results. These results offer research opportunities to further study conditions to reach and to prevent training success.

\section{Conclusion}

This manuscript offers an original contribution not previously addressed in literature regarding the method used in the research and the associated results provided. This study shows causal conditions leading to training success and causal conditions leading to less successful training results. There are three pathways leading to training success and two pathways leading to less successful training results. All five configurations contain exclusively core conditions, there are no peripheral conditions involved. Such findings show the importance of all conditions included in the pathways, strengthening the contribution they offer. Results suggest that training success depends on both the program and the trainees, while less successful training results originate essentially from program characteristics, and thus creating a challenge for HR and training managers. Additionally, when preparing training events, they have to satisfy four conditions, making pathways to training success quite demanding. Findings deliver an alert for HR and training managers when preparing training events due to pathways to less successful training results involving fewer conditions, and thus, being more possible/likely/easier to occur.

\section{Acknowledgement}

The authors are grateful for the support provided by FCT (Fundação para a Ciência e Tecnologia

- Portugal) under the project: UID/SOC/04521/2013

\section{References}

Bersin \& Associates (2012). Learning leaders is now the Bersin and Associates what works awards. Retrieved from http://bersin.com/wwawards/

BrandonHall Group. (2012). Winners of the 2012 Brandon hall excellence in learning awards. Retrieved from http://www.brandonhall.com/awards/excellence-in-learning/winners-of-the2012.html 
Cavus, N., \& Ibrahim, D. (2007). Assessing the success rate of students using a learning management system together with a collaborative tool in web-based teaching of programming languages. Journal of Educational Computing Research, 36(3), 301-321.

Cercone, K. (2008). Characteristics of adult learners with implications for online learning design'. AACE Journal, 16(2), 137-159.

Clark, R., Nguyen, F., \& Sweller, J. (2006). Efficiency in learning: Evidence-based guidelines to manage cognitive load. San Francisco, CA: Pfeiffer.

Cole, D., \& Espinoza, A. (2008). Examining the academic success of Latino students in science, technology, engineering, and mathematics (STEM) majors. Journal of College Student Development, 49, 285-300.

Crilly, D., Hansen, M., Pedersen, E., \& Perrini, F. (2012). Faking it or muddling through? Understanding decoupling in response to stakeholder pressures. Academy of Management Journal, 55(6), 1429-1449.

Crilly, D. (2011). Predicting stakeholder orientation in the multinational enterprise: A mid-range theory. Journal of International Business Studies, 42, 694-717.

DeBaz, T. (1994). Meta-analysis of the relationship between students' characteristics and achievement and attitudes toward science. Columbus, OH: ERIC Clearinghouse for Science, Mathematics, and Environmental Education. (ERIC Document ED377079).

Fiss, P. C. (2007). A set-theoretic approach to organizational configurations. Academy of Management Review, 32(4), 1180-1198.

Fiss, P. C. (2011). Building better causal theories: A fuzzy set approach to typologies in organization research. Academy of Management Journal, 54, 393-420.

Fiss, P. C., Sharapov, D., \& Conqvist, L. (2013). Opposites attract? Opportunities and challenges for integrating large-N QCA and econometric analysis. Political Research Quarterly, 66(1), 191-235.

Gagne, R. M., Briggs, L., \& Wager, W. W. (1992). Principles of instructional design. Fort Worth, TX: HBJ College Publishers

Grissom, J. B. (2004). Age and achievement. Education Policy Analysis Archives, 12(49).

Jaeger, A. J., \& Eagan, M. K. (2007). Exploring the value of emotional intelligence: A means to improve academic performance. NASPA Journal, 44(3), 512-537 
Kara, O., Bagheri, F., \& Tolin, T. (2011). Factors affecting students' grades in principles of economics. American Journal of Business Education, 2(7), 25-34.

Kaur, K., Chung, H. T., \& Lee, N. (2010). Correlates of academic achievement for master of education students at open university Malaysia. Proceedigns of the 6th Pan Commonwealth Forum on Open Learning, Kochi, India.

Keith, P. M., Byerly, C., Floerchinger, H., Pence, E., \& Thornberg, E. (2006). Deficit and resilience perspectives on performance and campus comfort of adult students. College Student Journal, 40(3), 546.

Keller, J. (2008). First principles of motivation to learn and e3-learning. Distance Education, 29(2), 175-185.

Kessels, U., Heyder, A., Latsch, M., \& Hannover, B. (2014). How gender differences in academic engagement relate to students' gender identity. Educational Research, 56(2), 220-229.

Merrill, D. (2002). First principles of instruction. Educational Technology Research and Devlopment, 50(3), 43-59.

Merrill, D. (2007). First principles of instruction: A synthesis. In R. A. Reiser \& J. V. Dempsey (Eds.), Trends and Issues in Instructional Design and Technology, 2nd Edition (Vol. 2, pp. 62-71). Upper Saddle River, NJ: Merrill/Prentice.

Meyer, A. D., Tsui, A. S., \& Hinings, C. R. (1993). Configurational approaches to organizational analysis. Academy of Management Journal, 36(6), 1175-1195.

Musa, M. A., \& Othman, M. S. (2012). Critical success factor in e-learning: An examination of technology and student factors. International Journal of Advances in Engineering \& Technology, 3(2), 140-148.

Park, J., \& Choi, H. J. (2009). Factors influencing adult learners' decision to drop out or persist in online learning. Journal of Educational Technology \& Society, 12(4), 207-217.

Pena, N., \& Isaias, P. (2012). The IPTEACES e-learning framework: Success indicators, the impact on student social demographic characteristics and the assessment of effectiveness. In P. Isaias, D. Ifenthaler, D. G. Sampson \& J. M. Spector (Eds.), Towards Learning and Instruction in Web 3.0 (pp. 151-169). New York, NY: Springer. http://dx.doi.org/:10.1007/978-1-4614-1539-8_10 
Pena, N., \& Isaias, P. (2013). Assessing the effectiveness of an e-learning framework: The Portuguese insurance academy case. Journal of Cases Information Technology, 15(1), 118.

Ragin, C. C. (2000). Fuzzy-set social science. Chicago, IL: Chicago University Press.

Ragin, C. C. (2005). From fuzzy sets to crisp truth tables. Tucson, AZ: Department of Sociology, University of Arizona.

Ragin, C. C. (2006). User's guide to fuzzy-set/qualitative comparative analysis 2.0. Tucson, AZ: Department of Sociology, University of Arizona.

Ragin, C. C. (2008). Redesigning social inquiry: Fuzzy sets and beyond. Chicago, IL: University of Chicago Press.

Rihoux, B., \& Ragin, C. C. (2009). Configurational comparative methods: Qualitative comparative analysis (QCA) and related research. Los Angeles, CA: Sage.

Schneider, C., \& Makszin, K. (2014). Forms of welfare capitalism and education-based participatory inequality. Socio-Economic Review, 12, 437-462.

van Merrienboer, J. J. G., \& Kirschner, P. A. (2007). Ten steps to complex learning. Mahwah, NJ: Lawrence Erlbaum Associates.

\section{Authors' Biographies}

Nuno Pena is a Chief Learning Officer, Invited Professor at ISEG - School of Economics and Management (Technical University of Lisbon) and Associated Researcher at ADVANCE Research Center (ISEG). Nuno finished his Postdoc in the field of Management Information Systems, holds a Ph.D. in Information Management, a Master degree in Multimedia Educational Communication; a Postgraduate certificate in Education (PGCE) and a Bachelor in Philosophy..

Carla Curado completed her Ph.D. and holds "Habilitation" in Management from the Technical University of Lisbon. She is an Associate Professor at the Department of Management, ISEG Lisbon School of Economics and Management, University of Lisbon. Her recent publications and current research are in Knowledge Management and Human Resources Management. 